\title{
Potential value of T1 mapping in cardiac MR assessment of hypertrophic cardiomyopathy and dilated cardiomyopathy patients: preliminary results
}

\author{
Alexis Jacquier ${ }^{1,2^{*}}$, Alexandros Kallifatidis ${ }^{1,2}$, Franck Thuny ${ }^{3}$, Jean Michel Bartoli², Boris Maurel ${ }^{2}$, Guy Moulin ${ }^{2}$ \\ From 15th Annual SCMR Scientific Sessions \\ Orlando, FL, USA. 2-5 February 2012
}

\section{Summary}

The purpose of this study is to assess the potential value of T1 mapping in assessing fibrosis in hypertrophic cardiomyopathy (HCM) and dilated cardiomyopathy (DCM) in comparison to late contrast enhanced imaging using cardiac MR.

\section{Background}

Myocardial fibrosis causes 1) increased stiffness and induces pathological signaling in cardiomyocytes resulting in progressive cardiac failure, 2)impairs mechanoelectric coupling of cardiomyocytes and increases the risk of arrhythmias. T1 mapping allow to quantify the total amount of myocardial extracellular volume and to subsequently define the amount of myocardial fibrosis. Quantification of fibrosis in dilated and hypertrophic cardiomyopathies and it's link to delayed myocardial enhancement is unclear.

\section{Methods}

Twelve patients with HCM, 10 with DCM, and 5 controls subjects were prospectively included. All patients underwent cardiac MR with the following sequences (parameters set according to recommendation of the SCMR): 1) cine sequence, 2) Molli sequence (TR/ $\mathrm{TE}=3.0 \mathrm{~ms} / 1.5 \mathrm{~ms}$; matrix $144 \times 150$, thickness: $7 \mathrm{~mm}$ ) acquired before and 5, 7, 9 min after gadolinium injection (DOTAREM, 0,2 $\mathrm{mmol} / \mathrm{kg}$ ). 3) Late gadolinium enhanced sequence $10 \mathrm{~min}$ after injection. T1 values were assessed in blood and in the 6 segments of the mid LV slice. Patient with (+) and without (-) enhancement on LGE were analysed separately. Were calculated: $\mathrm{R} 1, \Delta \mathrm{R} 1, \Delta \mathrm{R} 1$ ratio (partition coefficient of $\mathrm{Gd}, \lambda$ ).

\section{Results}

in controls before injection T1 value was $0,98 \mathrm{~s} \pm 0,05 \mathrm{~s}$ in myocardium, and $1,63 \mathrm{~s} \pm 0,08$ in blood. $\lambda$ was measured at $0.43 \pm 0,03$ in normal. In DCM, $\lambda$ was not significantly different between patient with $(0.51 \pm 0,04)$ and without $(0.50 \pm 0,05)$ enhancement on LGE $(p=0.2)$. In $\mathrm{HCM}, \lambda$ was significantly different between patient with $(0.54 \pm 0,08)$ and without $(0.45 \pm 0,05)$ enhancement on LGE ( $<<0.0001)$ (figure 1). No significant difference was measured in $\lambda$ value between control and HCM $(\mathrm{p}=0.1)$.

\section{Conclusions}

T1 mapping allow for quantification of the total amount of fibrosis in a myocardium. In DCM the distribution of fibrosis might be more diffused compared with HCM. These results have to be confirmed by larger study.

\section{Funding}

PHRC national 2011, AORC excelence 2011.

\section{Author details \\ ${ }^{1}$ CEMEREM, UMR 6612 CNRS, Marseille, France. ${ }^{2}$ Radiology, CHU Timone, \\ Marseille, France. ${ }^{3}$ Cardiology, CHU Timone, Marseille, France.}

Published: 1 February 2012 


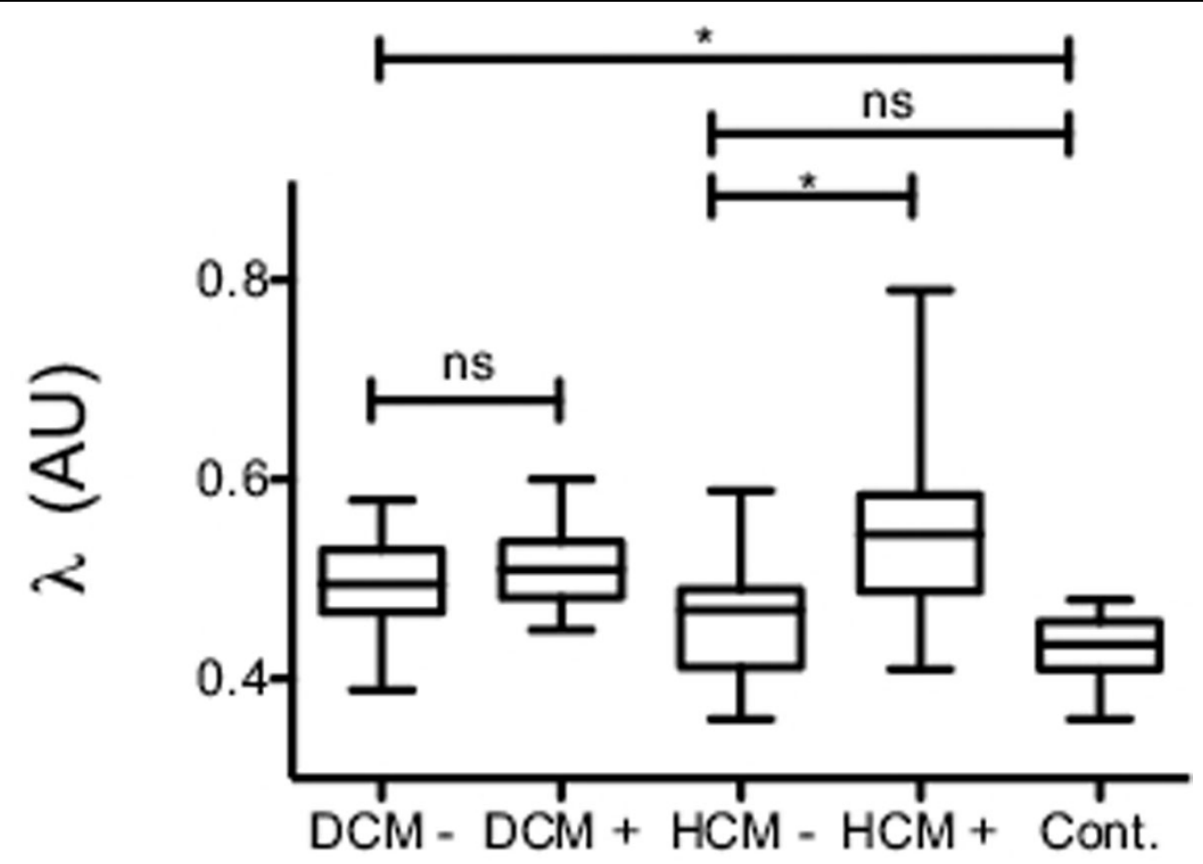

Figure 1 Graph showing the $\lambda$ value from different group.

doi:10.1186/1532-429X-14-S1-P145

Cite this article as: Jacquier et al:: Potential value of $\mathrm{T} 1$ mapping in cardiac MR assessment of hypertrophic cardiomyopathy and dilated cardiomyopathy patients: preliminary results. Journal of Cardiovascular Magnetic Resonance 2012 14(Suppl 1):P145.
Submit your next manuscript to BioMed Central and take full advantage of:

- Convenient online submission

- Thorough peer review

- No space constraints or color figure charges

- Immediate publication on acceptance

- Inclusion in PubMed, CAS, Scopus and Google Scholar

- Research which is freely available for redistribution 